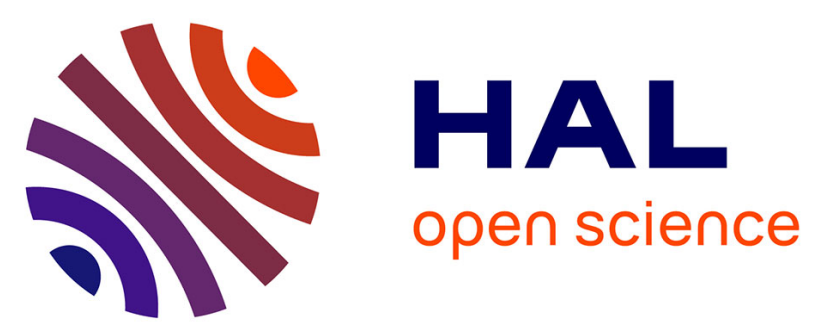

\title{
An assessment of the respective contributions of flow-rate and concentration variations to mass discharge variations at the outlets of two combined catchments during rain events
}

\author{
Claude Joannis, C. Joannis, Ali Hannouche, Ghassan Chebbo
}

\section{To cite this version:}

Claude Joannis, C. Joannis, Ali Hannouche, Ghassan Chebbo. An assessment of the respective contributions of flow-rate and concentration variations to mass discharge variations at the outlets of two combined catchments during rain events. Urban Water Journal, 2014, pp.7. 10.1080/1573062X.2014.939662 . hal-01061447

HAL Id: hal-01061447

https://hal-enpc.archives-ouvertes.fr/hal-01061447

Submitted on 5 Sep 2014

HAL is a multi-disciplinary open access archive for the deposit and dissemination of scientific research documents, whether they are published or not. The documents may come from teaching and research institutions in France or abroad, or from public or private research centers.
L'archive ouverte pluridisciplinaire HAL, est destinée au dépôt et à la diffusion de documents scientifiques de niveau recherche, publiés ou non, émanant des établissements d'enseignement et de recherche français ou étrangers, des laboratoires publics ou privés. 


\section{An assessment of the respective contributions of flow-rate and concentration variations to mass discharge variations at the outlets of two combined catchments during rain events}

C. Joannis*o, A. Hannouche**, G. Chebbo**,***

${ }^{\circ}$ corresponding author

* LUNAM, IFSTTAR - LEE, Département Géotechnique Eau,Risques naturels et Sciences de la terre - route de Bouaye - BP 4129 - 44341 Bouguenais cedex, France (E-mail: claude.joannis@ifsttar.com)

**Université Paris-Est, LEESU, UMR-MA-102, Agro ParisTech, 6 et 8 avenue Blaise Pascal - Cité Descartes, 77455 Champs-sur-Marne Cedex 2, France (E-mail: ali.hannouche@leesu.enpc.fr, ghassan.chebbo@leesu.enpc.fr)

***Faculty of Engineering III, Lebanese University, Rafic Hariri University campus, Hadath Lebanon 


\section{An assessment of respective contributions of flow-rate and concentration variations to mass discharge variations at the outlets of two combined catchments during rain events}

This paper presents a method for assessing the respective contributions of the variations of flow-rate and concentration of any pollution parameter to the variations of the mass discharge of the same parameter. This method uses a specially designed decomposition of variance, which gives a priority to the information provided by flow-rates, either directly, or through the correlation between flow-rates and concentrations. To demonstrate the potential interest of this method, data monitored on two catchments in the city of Paris (France) are processed according this method, with turbidity being used as a surrogate for suspended solids concentration. Results show that volumes provide a fairly good evaluation of masses at the scale of whole events. Inside any particular event, concentrations are major contributors to the variations of mass discharge, despite the correlations between flow rate and concentration which may be observed for many rain events.

Keywords: Mass discharge, flow-rate, concentration, turbidity, variance, rain event

\section{Introduction}

Monitoring sewer systems for performance assessment or real time control is becoming more common (EPA 1998, Schuetze et al. 2008, Dirckx et al. 2011). Monitoring of fluxes conveyed by sewerage may consider flow-rates time series (hydrographs) and/or concentrations time 
series (pollutographs) measured on facilities which discharge waste waters into receiving waters or convey them towards treatment plants. In both cases, monitoring is performed for calibrating or validating models, and/or real time control of particular facilities.

Regarding the performance assessment of combined sewer overflow (CSO) facilities, French regulations (OJ, 2007) require that water discharge be continuously measured during CSO events and water quality merely be merely assessed. The means suitable for this latter assessment are not specified, but the formulation suggests that measuring concentrations has a lower priority or a lower value for money than measuring flow-rates. Actually many methods and devices are available for measuring flow-rates, whereas measuring concentration with a proper representativeness is more difficult and expensive (Bertrand-Krajewski et al., 2000). Moreover, overflowed volumes are an interesting indicator for assessing the potential impact of CSO on receiving waters (Engelhart at al. 2009, Lau et al. 2002).

This paper presents and evaluates a method for assessing the extra information brought by concentration measurements once flow-rate measurement is available. The elaboration of the method is fully described, then data recorded in the combined sewer system of Paris (France) are processed as an application example, and results are discussed.

\section{Calculation method}

\subsection{Variance decomposition for a product}

Mass discharge $\Phi(t)$ of any pollutant can be expressed as $\Phi(t)=Q(t) * C(t)$ where $Q$ denotes water flow-rate and $C$ the concentration of the considered pollutant, both as functions of time. All variables may be defined as instant values at time $t$ or averaged over a period of time $[t$, $t+\Delta t]$, where $\Delta t$ is a constant time-step. In the latter case concentrations should be weighted by flow-rates in the averaging process, for a correct calculation of average mass-discharge. 
In most situations, monitoring aims at assessing variations. We thus focus on the contributions to the variance of mass discharge inside any particular rain event, which is handier to express as squared variation coefficient named normalised variance in the following text.

Hannouche (2012) demonstrated that variation coefficients $(C v)$ of mass-discharge

$C v_{\Phi}$, flow-rate $C v_{Q}$ and concentrations $C v_{C}$ are linked by the following equation:

$$
C v_{\Phi}^{2}=\frac{\sigma_{\Phi}^{2}}{\bar{Q}^{2} \cdot \bar{C}^{2}} \frac{1}{\left(1+\varepsilon_{2}\right)^{2}}=\frac{C v_{C}^{2}+C v_{Q}^{2}+2 \rho_{Q, C} \cdot C v_{C} \cdot C v_{Q}+\varepsilon_{1}}{\left(1+\varepsilon_{2}\right)^{2}}
$$

$\varepsilon_{1}$ is a second order term which cannot be developed here (see Appendix).

$\varepsilon_{2}=\bar{\Phi}-\bar{Q} \cdot \bar{C}$, where $\bar{\Phi}, \bar{Q}$ and $\bar{C}$ are average values of $\Phi(t), Q(t)$ and $C(t)$ calculated over the duration of the considered rain event.

$\rho_{Q, C}$ is the correlation coefficient between $Q(t)$ and $C(t)$ calculated for the same rain event.

We now consider the impact of neglecting either $\varepsilon_{1}$ or $\varepsilon_{2}$ in equation (1). $\left(1+\varepsilon_{1}\right)$ is a scaling factor, which only influences the expression of $\sigma_{\Phi}^{2}$ as a dimensionless variable, thus neglecting $\varepsilon_{2}$ has no effect on the relative contributions to the variance of mass discharge. By contrast neglecting $\mathcal{E}_{1}$ has a direct influence on the expression of mass discharge variance given by the numerator: the very idea of identifying contributions to $C v_{\Phi}^{2}$ assumes that $\varepsilon_{1}$ is actually negligible when compared to the other components of $\sigma_{\Phi}^{2}$.

In the "Results" section, $\varepsilon_{1}$ will be called "balance error" and $\varepsilon_{2}$ "scaling error", and the legitimacy of both approximations will be verified. 
If $\varepsilon_{1}$ and $\varepsilon_{2}$ are neglected, equation (1) reads: $C v_{\Phi}^{2} \approx C v_{C}^{2}+C v_{Q}^{2}+2 \rho_{Q, C} \cdot C v_{C} \cdot C v_{Q}$

Calculations presented here above focus on variations of $Q(t), C(t)$ and $\Phi(t)$ inside one particular rain event. They can easily be transposed for assessing variations between rainevents by integrating $Q(t), C(t)$ and $\Phi(t)$ over the duration of each particular rain event. Then, mass-discharge and flow-rate are replaced in equation (2) by mass and volume respectively to get:

$$
C v_{M}^{2} \approx C v_{C}^{2}+C v_{V}^{2}+2 \rho_{V, C} \cdot C v_{C} \cdot C v_{V}
$$

with $M$ : total mass, $V:$ total volume, and $C=M / V:$ mean concentration of any rain event.

Both equations (2) and (3) are a sum of three terms, which might be interpreted as contributions of flow-rate, concentration and Q-C correlation, respectively to the variations of either mass-discharge or event masses. Actually this interpretation is not suitable for assessing the extra information brought by concentration in case flow-rate is known. For instance, in a hypothetic situation where $\mathrm{C}$ and $\mathrm{Q}$ are perfectly correlated and proportional $(C=a . Q)$, flowrate would be sufficient to express mass-discharge as a quadratic function $\Phi=a \cdot Q^{2}$. Then the extra contribution of $C$ to mass discharge variations will be zero provided that the coefficient $a$ is known. In this case $\mathrm{Q}$ should be considered the only contributor to mass-discharge variations, either directly, or through the covariance between Q and C. Yet the contributions derived from equation (2) would be $25 \%$ from concentration, $25 \%$ from flow-rate, and $50 \%$ for Q-C correlation. To overcome this discrepancy we turned to a geometrical interpretation. In the following, the extra contribution of concentration to mass discharge normalised variance is named concentration marginal contribution. 


\subsection{Geometrical interpretation of variance decomposition}

Figure 1 is a geometrical interpretation of equation (2) which is adapted from the classical interpretation of the variance of a sum of two variables by transforming standard deviations into their corresponding variation coefficients.

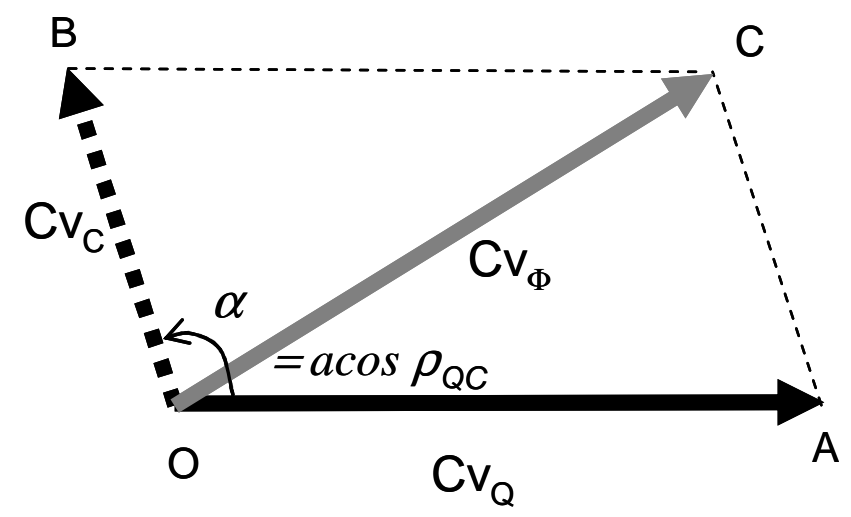

Figure 1. Interpretation of the variance of a product, namely mass-discharge $\Phi$ as a product of a flow-rate $Q$ by a concentration $C$

This construction is somewhat difficult to interpret because the contributions to the normalised variance of mass-discharge are expressed as squared variation coefficients, which correspond to the squared modules of $\overrightarrow{O A}, \overrightarrow{O B}$ and $\overrightarrow{O C}$ vectors. Thus, we searched for a projection method, which could express the contributions as (algebraic) lengths rather than squared modules. Figure 2 shows the proposed decomposition. $\overrightarrow{O A}$, representing flow-rate variations, is directly projected on $\overrightarrow{O C}$, whereas $\overrightarrow{O B}$, representing concentration variations, is split into two components, which are then projected on $\overrightarrow{O C}$ :

- $\overrightarrow{O B}_{1}$ is perpendicular to $\overrightarrow{O A}$ and represents the part of concentrations variations which is (linearly) independent of flow-rate;

- $\overrightarrow{O B}_{2}$ is collinear with $\overrightarrow{O A}$ and represents the part of concentrations variations which is (linearly) linked to flow-rate. 


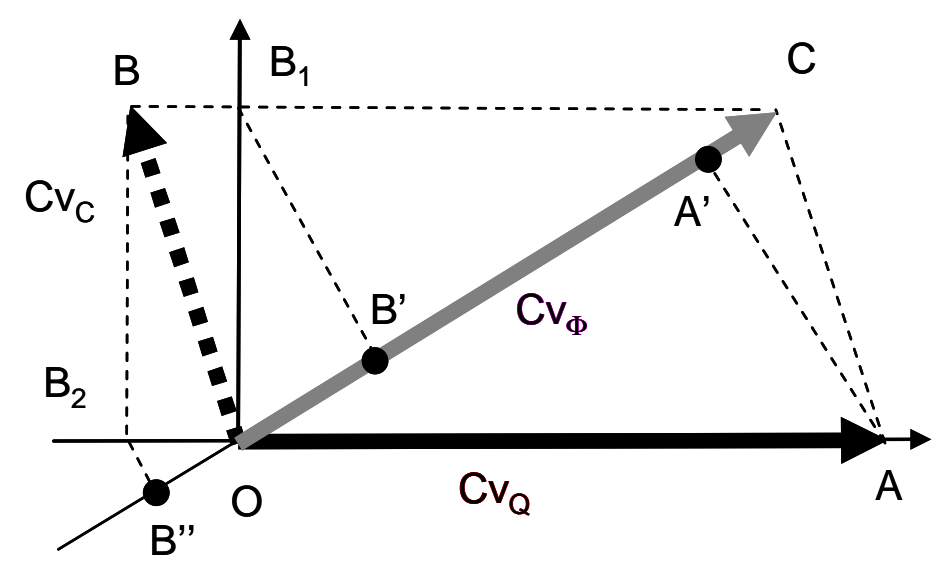

Figure 2: Proposed interpretation of the contribution to mass-discharge normalised variance

The concentration marginal contribution is represented by $\left|\overrightarrow{O B^{\prime}}\right|$, whereas the overall contribution of flow-rate is represented by $\left|\overrightarrow{O A^{\prime}}+\overrightarrow{O B^{\prime \prime}}\right|$. When interpreting the results we will however keep a distinction between the two components of flow-rate contribution, because the information contained in flow-rate data is transferred into mass discharge through two different pathways:

- a direct pathway, coming from $Q$ term in $\Phi=Q * C$ formula;

- an indirect pathway, by the means of $Q-C$ correlation.

The practical implications of both pathways are very different and will be detailed in the results section.

The analytical expressions of the three contributions to mass discharge variations are:
- Flow-rate direct contribution
$(\%): \quad \frac{\overline{O A^{\prime}}}{\overline{O C}}=\frac{C v_{Q}^{2}+\rho_{Q, C} \cdot C v_{Q} \cdot C v_{C}}{C v_{\Phi}^{2}}$
- Flow-rate indirect contribution

$$
(\%): \frac{\overline{O B^{\prime \prime}}}{\overline{O C}}=\frac{\rho_{Q, C}^{2} \cdot C v_{C}^{2}+\rho_{Q, C} \cdot C v_{Q} \cdot C v_{C}}{C v_{\Phi}^{2}}
$$


- Concentration marginal contribution $(\%): \quad \frac{\overline{O B^{\prime}}}{\overline{O C}}=\frac{C v_{C}^{2}\left(1-\rho_{Q, C}^{2}\right)}{C v_{\Phi}^{2}}$

We verified the consistency of the proposed decomposition for extreme cases. If the covariance between $Q$ and $C$ is zero, the contribution of either $Q$ or $C$ is equal to their normalised variance divided by the normalised variance of mass discharge. If $Q$ and $C$ are perfectly correlated, especially if $C=a . Q$, the marginal contribution of concentration is zero, whereas the direct and indirect contribution of flow-rate are equivalent.

\section{Data}

The outlets of two catchments, Quais and Clichy, were monitored in the framework of OPUR (Observatoire des Polluants URbains en Île-de-France - Observatory of Urban Pollutants in Île-de-France/Paris region) research program, which addresses the generation, transport and treatment of pollutant loads due to storm water runoff and wastewater discharge. The main features of both catchments are summarised in Table 1.

Table 1. Main features of the monitored catchment

\begin{tabular}{ccc}
\hline Catchments & Quais & Clichy \\
\hline Area (ha) & 402 & 942 \\
Hydraulic length (Km) & 5 & 9 \\
Median slope & $0.14 \%$ & $0.10 \%$ \\
Runoff factor (-) & 0.64 & 0.68 \\
population density (ha $\left.{ }^{-1}\right)$ & 200 & 215 \\
Average daily flow (m $\left.{ }^{3} / \mathrm{s}\right)$ & 0.7 & 2.4 \\
Average daily water level (m) & 1.4 & 1.8 \\
\hline
\end{tabular}


Both catchments are typically urban (with a runoff factor of 0.64 for Quais and 0.68 for Clichy) and extend over an area of 402 ha for Quais and 942 ha for Clichy (Quais catchment is totally embedded in the Clichy catchment). The sewer system in Paris is known for deposition of solids, as deposits contribute up to $40 \%$ to suspended solids (SS) discharge during rain events (Gromaire et al., 2001, Hannouche et al., 2014, in press).

Flow rates are monitored in real time by the Paris Municipal Sewerage Department" by the means of $C R 2 M$ ultrasonic time-of-flight flow meters. At "Quais" site, the average daily dry weather flow equals $0.7 \mathrm{~m}^{3} \cdot \mathrm{s}^{-1}$ and can potentially reach $4 \mathrm{~m}^{3} \cdot \mathrm{s}^{-1}$ during rainfall events and at "Clichy" site, it equals $2.4 \mathrm{~m}^{3} \cdot \mathrm{s}^{-1}$ and can potentially reach $6 \mathrm{~m}^{3} \cdot \mathrm{s}^{-1}$ during rainfall events.

Both sites were fitted with Martec-Ponselle turbidimeters. These sensors measure the attenuation of an infrared beam with a wavelength of $880 \mathrm{~nm}$ and are operated in the range 0 2000 FAU. A special attention was paid to justify the reliability and quality of turbidity data. Prior to their installation, the sensors were calibrated using laboratory-prepared Formazin standards. The application of detailed protocols leads to calibrating uncertainties at less than 3\% (Joannis et al., 2008). When in situ, the optical devices of the turbidity sensor are automatically cleaned 4 times an hour. In addition, the instrumentation system is cleaned and maintained every other week by a technical team. Zero drift and endpoint calibration are checked as well. The final turbidity signal is derived by comparing differences between the two available redundant raw data series, a step that enables efficiently rejecting noisy spikes. In the remainder of this paper, turbidity data will be assimilated to concentrations, by applying a mean conversion factor $0.82 \mathrm{mg} \cdot \mathrm{L}^{-1} \cdot \mathrm{FAU}^{-1}$. Actually the value of this factor is not so important as far as concentration and mass-discharge variations are concerned. The important feature is that its value is considered as being constant. According to Hannouche et 
al. (2011), this assumption is legitimate inside any particular rain event, but more questionable when the variability between rain events is considered.

Turbidity, conductivity and hydraulic flow were all monitored with a 1-minute time step for a full year of data without interruption. Rainfall data from two nearby rain gauges were also available. Each storm event was delimited by processing flow rate and conductivity data. The beginning of the event was characterised by a flow rise that occurred simultaneously with an abrupt conductivity signal drop (due to the presence of high storm water volumes in combined effluent) and the end of the event by a return to the dry weather flow level. Data were processed and validated by Lacour (2009).

Seventy-five rain events were identified for "Quais" site and eighty eight for "Clichy" site, among which seventy events were available on both sites. Table 2 displays overall characteristics of all available rain events, most of which can be characterized as small rainfalls proceeded by fairly short dry periods. Total rainfalls over the duration of each event have a return period of one month for $25 \%$ of the events, and 3 months for $10 \%$ of the events. Such short return periods are indeed those considered for service levels \#1 and \#2 for sewer design and operation, defined by French guidelines (CERTU, 2003) as "no overflow allowed" and "accepted and controlled overflows" respectively.

Table 2. Characteristics of rain events identified for this study

\begin{tabular}{cccccc}
\hline & $\begin{array}{c}\text { Total rainfall } \\
(\mathrm{mm})\end{array}$ & $\begin{array}{c}\text { Mean } \\
\text { Intensity } \\
\left(\mathrm{mm} \cdot \mathrm{h}^{-1}\right)\end{array}$ & $\begin{array}{c}\text { Max } 5 \mathrm{mn} \\
\text { Intensity } \\
\left(\mathrm{mm}^{-1} \mathrm{~h}^{-1}\right)\end{array}$ & $\begin{array}{c}\text { Rain event } \\
\text { duration } \\
(\mathrm{h}: \mathrm{min})\end{array}$ & $\begin{array}{c}\text { antecedent dry } \\
\text { period } \\
(\text { days })\end{array}$ \\
\hline $\mathrm{d}_{10}$ & 1.2 & 1.0 & 2.3 & $0: 30$ & 0.26 \\
Median & 4.5 & 1.8 & 8.8 & $1: 40$ & 1.41 \\
$\mathrm{~d}_{90}$ & 11.7 & 6.4 & 61.6 & $9: 10$ & 5.63 \\
\hline
\end{tabular}




\section{Results}

\subsection{Contributions to mass variations between rain events}

Table 3 provides details about the calculations of the different contribution to mass normalised variance for Quais and Clichy sites. It shows that concentration variations contribute only by $15-20 \%$ to mass variations: volume variations between rain events are the main source of mass variations. Actually the small negative correlation values between volumes and concentrations show that concentration variations slightly compensate for the effect of volumes variations, lowering the raw contributions of volumes from $93-94 \%$ to 88 $89 \%$ and leading to overall contributions of volumes around $85 \%$ for both sites. It is also verified that the approximations involved in these assessment are quite acceptable.

Table 3. Contributions to mass normalised variance between rain events at Quais et Clichy. ( $\varepsilon_{1}$ and $\varepsilon_{2}$ are defined in the "calculation methods" section). All values except $\rho_{Q, C}$ are expressed as \%.

\begin{tabular}{|c|c|c|c|c|c|c|c|c|c|}
\hline \multirow[t]{2}{*}{ Site } & \multirow[t]{2}{*}{$\rho_{Q, C}$} & \multirow[t]{2}{*}{$\frac{C v_{Q}^{2}}{C v_{\Phi}^{2}}$} & \multirow[t]{2}{*}{$\frac{2 \rho_{Q, C} \cdot C v_{C} \cdot C v_{V}}{C v_{\Phi}^{2}}$} & \multirow[t]{2}{*}{$\frac{C v_{C}^{2}}{C v_{\Phi}^{2}}$} & $\begin{array}{c}\text { Direct } \\
\text { contribution } \\
\text { of volume }\end{array}$ & $\begin{array}{c}\text { Indirect } \\
\text { contribution } \\
\text { of volume }\end{array}$ & $\begin{array}{c}\text { Concentration } \\
\text { marginal } \\
\text { contribution }\end{array}$ & \multicolumn{2}{|c|}{ 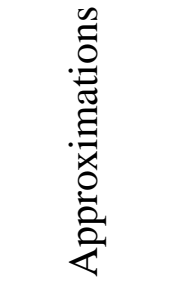 } \\
\hline & & & & & $\frac{\left[\begin{array}{l}C v_{V}^{2}+ \\
\rho_{Q, C} \cdot C v_{C} \cdot C v_{V}\end{array}\right]}{C v_{\Phi}^{2}}$ & $\frac{\left[\begin{array}{l}\rho_{Q, C}^{2} \cdot C v_{C}^{2}+ \\
\rho_{Q, C} \cdot C v_{C} \cdot C v_{V}\end{array}\right]}{C v_{\Phi}^{2}}$ & $\frac{C v_{C}^{2} \cdot\left(1-\rho_{Q, C}^{2}\right)}{C v_{\Phi}^{2}}$ & $\frac{\varepsilon_{1}}{C v_{\Phi}^{2}}$ & $\frac{\varepsilon_{2}}{C v_{\Phi}^{2}}$ \\
\hline Quais & $-0,14$ & 93 & -11 & 18 & 88 & -5 & 18 & 4 & -3 \\
\hline Clichy & $-0,12$ & 94 & -9 & 15 & 89 & -4 & 15 & -3 & -2 \\
\hline
\end{tabular}

These results may support the use of a site mean concentration (SMC) model (Adams \& Papa, 2000), for assessing event masses on these sites. According to this model the event mean concentration is considered to be constant with time, but it must be calibrated for each 
particular site. Concentration measurements are needed for this calibration purpose and the accuracy of mass evaluations obtained depends on the representativeness of the calibrated mean concentration. When the mean is derived from continuous measurements spreading over several dozens of rain events, the evaluations may be approximate for each particular rain event but become quite satisfactory when event masses are cumulated for assessing an annual mass (Lacour et al., 2009).

\subsection{Contributions to mass discharge variations inside rain events}

Figure 3 shows the normalised standard deviation of mass-discharge and the different relative contributions to the normalised variance of mass discharge for each rain event on both sites. The reliability of results is also presented: events for which the balance error $\varepsilon_{1}$ term is larger than $20 \%$ of the normalised variance are highlighted by black dots. Actually $90 \%$ of $\varepsilon_{1}$ values are in the range $[-25 \% ;+6 \%]$ on both sites, whereas $90 \%$ of scaling errors $\left(\varepsilon_{2}\right)$ values stay in the range $[0 \% ;+9 \%]$

Respective contributions of flow-rate and concentrations to mass-discharge variations are more balanced inside rain events than between rain events, especially at Quais site: for 29 rain events among 77, and 23 rain events among 88 at Clichy site, the contribution of concentration is at least $33 \%$ of the normalised variance of mass-discharge. It may be pointed out that rain events with a significant contribution of concentration variations have a rather low mass-discharge normalised variance. 

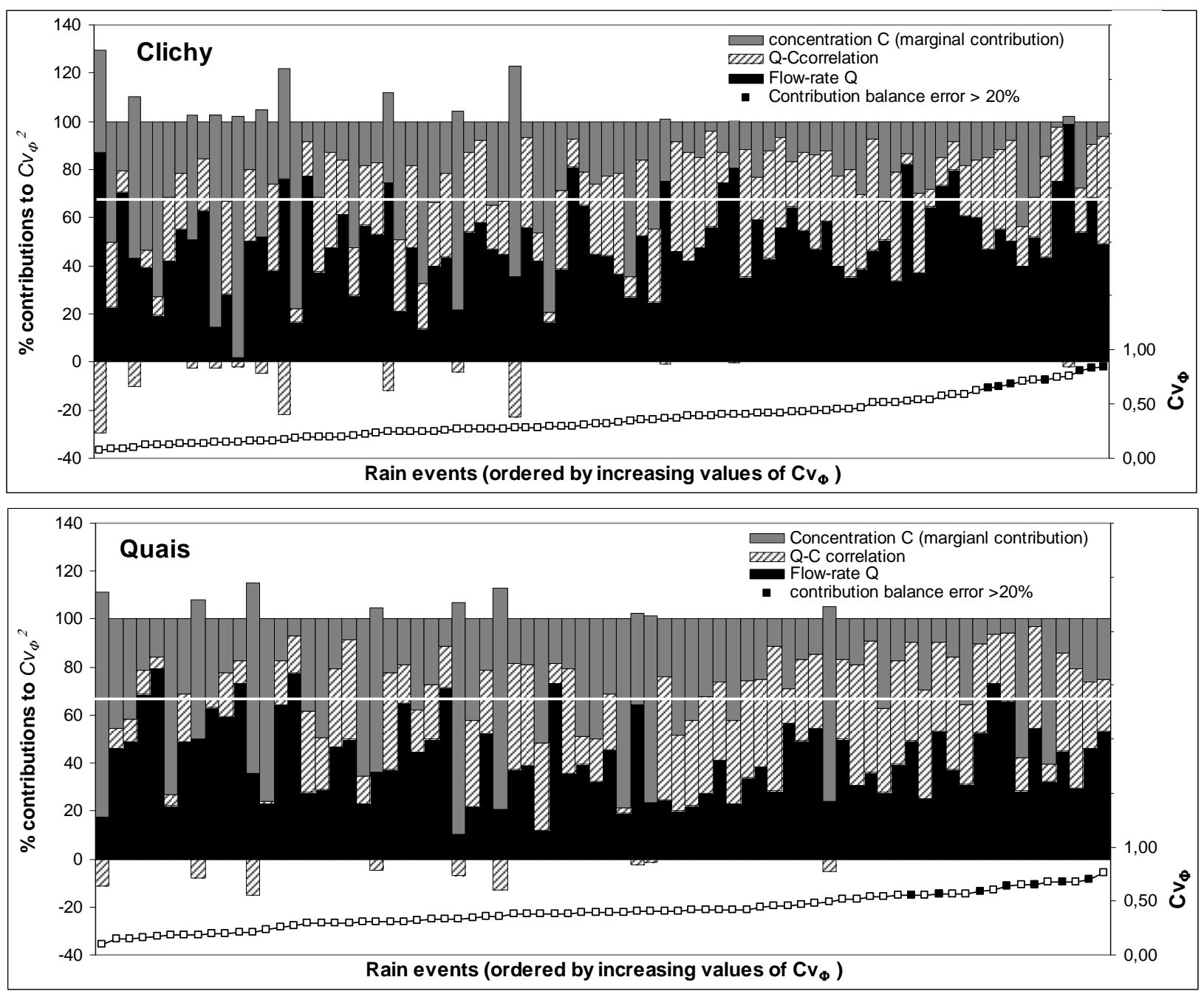

Figure 3. Contributions to normalised variance of mass-discharge inside all available rain events. The white line provides a conventional reference level $(66 \%)$ for contributions. Black dots on $C v_{\Phi}$ curves indicates approximations larger than $20 \%$

Moreover flow-rate variations have a major (more than 66\%) direct contribution to mass-discharge variations for only 15 rain events at Clichy and 7 at Quais. For most rain events, and especially those which display a high variability of mass-discharge, the correlation of concentration with flow-rate inside each particular rain event contributes significantly to the total contribution of flow-rate variations. This means that in most cases dilution processes are shadowed by other processes like flushing of deposits. More over for rain events where a negative correlation does exist, the determination coefficients are low $\left(\rho^{2}\right.$ $<0.5)$ and the contributions of the correlations are rather small. Actually the interpretation of 
the variance decomposition becomes fairly awkward when negative correlations are involved, because this leads to a negative contribution, the meaning of which is not straightforward. For example in an ideal situation where only dilution processes are involved, the mass discharge is constant, and the information brought by flow-rate and concentration are both annihilated by their negative correlation. This is a limitation of the method, which is best suited to the cases where the correlation between flow-rate and concentration is positive or null.

Correlations between concentration and flow-rate can be used to assess massdischarges from flow-rates only if these correlations are predictable, and preferably remain constant. Table 4 provides average values and standard deviations of the parameters of the regressions calculated on both sites for each rain event, except those for which the contribution of $Q-C$ correlation is lower than 25 . The scattering of parameter values from one rain event to another is quite large, making it impossible to apply a unique flow-rate to concentration relationship. The first attempts made to predict correlation parameters from rain event characteristics did not succeed. Hence $Q-C$ correlations have little practical interest for assessing mass discharge variations inside rain events.

Table 4. Average (AV) and standard deviations (SD) of parameters $a$ and $b$ in the regression formulas $\mathrm{T}=\mathrm{a} . \mathrm{Q}+\mathrm{b}(\mathrm{T}:$ turbidity ; $\mathrm{Q}$ : flow-rate) calculated for selected rain events

\begin{tabular}{lcccc}
\hline & AV(a) & SD (a) & AV(b) & SD(b) \\
\hline Quais (n=18) & 224 & 128 & -46 & 125 \\
Clichy (n=20) & 72 & 30 & 42 & 65 \\
\hline
\end{tabular}

\section{Conclusion}

A method was developed to decompose the variance of a product which can be applied for identifying and assessing different contributions to mass-discharge variations inside any particular rain event and between different rain events. These contributions are: 
- a direct contribution of flow-rate variation, which comes from the flow-rate term in the expression of mass-discharge;

- an indirect contribution of flow-rate variation, which is a consequence of the correlation between concentration and flow-rate ;

- a residual contribution of concentrations variations, after deduction of the fraction which is a linear function of flow-rate.

This method was applied to two sets of data from two combined catchments in Paris (respectively 75 and 88 rain events for which flow-rate and turbidity recordings were available).

The most meaningful information derived from the proposed decomposition is the direct contribution of flow-rate. The results obtained clearly show that this contribution is quite significant for variations between rain events, and much lower inside rain events.

By comparison the indirect contribution of flow-rate has less practical interest than the direct one, as it is mainly potential and cannot be harnessed in many cases because the correlations between concentration and flow-rates are costly to establish for particular rain events. Moreover they lack reproducibility from one rain event to another. Lastly, this indirect contribution only considers linear models between flow-rate and concentration (or quadratic models between-flow-rate and mass discharge) and it is difficult to interpret when it has negative values.

These results suggest that a site mean concentration model might be sufficient on the considered sites for assessing event masses, or preferably annual masses, from volumes. They also demonstrate that on the same sites the flow-rate is not sufficient for assessing massdischarge variations inside a particular rain event. Thus, the value of concentration measurements is confirmed, provided that a good temporal sampling is achieved. 
Such analysis could be performed on a preliminary campaign of turbidity and flowrates measurements in order to assess the extra value brought by a (continuous) concentration measurements, and design permanent monitoring facilities. It might as well provide some clues for modelling, by identifying two pathways for the influence of flow rates on massdischarge. In both cases, turbidity recordings should be performed over a period of time long enough to get a representative sample of rain events according to the objectives of the monitoring. A full year is a minimum basis but it is better to target a significant number of rain events whose features are suited to the objectives, with a special focus on sampling largest events. When such data sets are available on different sites with different characteristics, the conclusions about the respective contributions of different sources of information on mass discharges outlined in this paper will be reconsidered.

\section{Acknowledgments}

The authors gratefully acknowledge the partners of OPUR, OTHU and ONEVU field observatories and SEPIA Conseils firm for their combined financial and technical support.

\section{References}

Adams, B.J. and Papa, F. 2000 Urban stormwater management planning with analytical probabilistic models. John Wiley and Sons. Toronto.

OJ, 2007, «Arrêté du 22 juin 2007 relatif à la collecte, au transport et au traitement des eaux usées des agglomérations d'assainissement ainsi qu'à la surveillance de leur fonctionnement et de leur efficacité [...] » (French decree of 22 June 2007 concerning the collection, the transportation and the treatment of wastewater as well as the supervision of their working and efficiency [...])., Official Journal of French Republic, (162), 11937-11951 
Bertrand-Krajewski, J.-L., Laplace, D., Joannis, C., and Chebbo, G. 2000 Mesures en hydrologie urbaine et assainissement. Edition TEC \& DOC/Lavoisier, Paris, France (ISBN 2743003804).

CERTU, 2003, La ville et son assainissement - Principes, méthodes et outils pour une meilleur intégration dans le cycle de l'eau (City drainage - guidelines, methods and tools for a better integration into the water cycle). CD-ROM (available http://www.developpementdurable.gouv.fr/IMG/pdf/DGALN_Ville_assainissement_so.pdf accessed December $\left.8^{\text {th }}, 2013\right)$.

Dirckx G., Thoeye Ch., De Gueldre G., Van De Steene B. 2011 CSO management from an operator's perspective: a step-wise action plan, Water Science and Technology, 63(5), 1044-1052.

Engelhard C., De Toffol S., Rauch W. 2008 Suitability of CSO performance indicators for compliance with ambient water quality targets, Urban Water Journal, 5(1): 43-49

Gromaire,M. C., Garnaud, S., Saad, M. \& Chebbo, G. 2001 Contribution of different sources to the pollution of wetweather flows in combined sewers, Water Research, 35 (2), $521-533$

Hannouche A., Chebbo G., Ruban G., Tassin B., Lemaire B., Joannis C., 2011, Relationship between turbidity and total suspended solids concentration within a combined sewer system, Water Science and Technology, 64 (12), 2445-52

Hannouche A. 2012 «Analyse du transport solide en réseau d'assainissement unitaire par temps de pluie : exploitation de données acquises par les observatoires français en hydrologie urbaine » (Analysis of solid transport in combined sewer network during wet weather: exploitation of data acquired by the French observatories in urban hydrology), PhD Thesis, Universite Paris-Est, France, 485p.

Hannouche, A., Chebbo, G., Joannis, C. 2014, "in press". Assessment of the contribution of sewer deposits to suspended solids loads in combined sewer systems during rain events. CABRRES project: Chemical, microbiological, spatial characteristics and impacts of 
contaminants from urban catchments (DOI 10.1007/s11356-013-2395-1). Environmental Science and Pollution Research.

Joannis, C., Ruban, G., Gromaire, M.C., Bertrand-Krajewski, J.L., Chebbo, G. 2008. Reproducibility and uncertainty of wastewater turbidity measurements. Water Science and Technology, 57(10), 1667-1673.

Lacour C., Joannis C., Gromaire M.-C., Chebbo G. 2009a Potential of turbidity monitoring for real time control of pollutant discharge in sewers during rainfall events, Water Science and Technology, 59(8), 1471-1478

Lacour C., Joannis C., Chebbo G. 2009b Assessment of annual pollutant loads in combined sewers from continuous turbidity measurements: sensitivity to calibration data, Water Research, 43(8), 2179-2190

Lacour, C. 2009 Apport de la mesure en continu pour la gestion de la qualité des effluents de temps de pluie en réseau d'assainissement (Contribution of continuous turbidity measurements to the management of effluent quality in sewer systems during wet weather). PhD Thesis, Universite Paris-Est, France, 309p.

Lau, J., Butler, D. and Schuetze, M. 2002 Is combined sewer overflow spill frequency/volume a good indicator of receiving water quality impact? Urban Water Journal, 4(2), 181189

Schütze M., Erbe V., Haas U., Scheer M., Weyand M. 2008 Sewer system real-time control supported by the M180 guideline document, Urban Water Journal, 5(1), 69-78

USEPA 1999 Combined Sewer Overflows Guidance for Monitoring and Modeling; http://www.epa.gov/npdes/pubs/sewer.pdf, accessed 19 Feb. 2013) 


\section{Appendix: demonstration of Equation 1}

In the following, we consider $\Phi$ (mass discharge), $Q$ (flow-rate) and $C$ (concentration) as random variables and $\Phi_{i}, Q_{i}$ et $C_{i}$ their respective realisations, sampled at time $t_{i}$. We choose the variance of mass discharge as a reference for the information provided by flow-rate and concentration measurements.

If $\bar{Q}$ et $\bar{C}$ are the mean values of $Q$ and $C$ respectively, $Q_{i}$ and $C_{i}$ can be expressed

as :

$Q_{i}=\bar{Q}+\Delta Q_{i}$ and $\square$;

Then :

$\Phi_{i}=Q_{i} \cdot C_{i}=\bar{Q} \cdot \bar{C}+\bar{Q} \cdot \Delta C_{i}+\bar{C} \cdot \Delta Q_{i}+\Delta Q_{i} \cdot \Delta C_{i}$

If $\sigma_{Q}$ and $\sigma_{C}$ are standard deviations of $Q$ and $C$ respectively, and $\sigma_{Q, C}$ their covariance then:

$$
\sigma_{Q}=\sigma_{\Delta Q} ; \sigma_{C}=\sigma_{\Delta C} ; \sigma_{Q, C}=\sigma_{\Delta Q, \Delta C}
$$

The correlation coefficient between $Q$ and $C$ is defined as $\rho_{Q, C}=\frac{\sigma_{Q, C}}{\sigma_{Q} \cdot \sigma_{C}}$ and we get:

$$
\rho_{Q, C}=\rho_{\Delta Q, \Delta C}
$$

The standard deviation of mass-discharge can be expressed as:

$$
\sigma_{\Phi}^{2}=\bar{Q}^{2} \cdot \sigma_{C}^{2}+\bar{C}^{2} \cdot \sigma_{Q}^{2}+2 \cdot \bar{Q} \cdot \bar{C} \cdot \sigma_{Q, C}+\varepsilon_{1}^{\prime}=\bar{Q}^{2} \cdot \sigma_{C}^{2}+\bar{C}^{2} \cdot \sigma_{Q}^{2}+2 \cdot \bar{Q} \cdot \bar{C} \cdot \rho_{Q, C} \cdot \sigma_{Q} \cdot \sigma_{C}+\varepsilon^{\prime}{ }_{1}
$$

with $\varepsilon_{1}^{\prime}$, sum of second order terms: 


$$
\varepsilon_{1}^{\prime}=\operatorname{cov}^{2}(\Delta Q \cdot \Delta C)+2 \bar{Q} \cdot \operatorname{cov}(\Delta Q, \Delta Q \cdot \Delta C)+2 \bar{C} \cdot \operatorname{cov}(\Delta C, \Delta Q \cdot \Delta C)
$$

Dividing by $\bar{Q}^{2} \cdot \bar{C}^{2}$ gives :

$$
\frac{\sigma_{\Phi}^{2}}{\bar{Q}^{2} \cdot \bar{C}^{2}}=\frac{\sigma_{C}^{2}}{\bar{C}^{2}}+\frac{\sigma_{Q}^{2}}{\bar{Q}^{2}}+2 \rho_{Q, C} \cdot \frac{\sigma_{Q}}{\bar{Q}} \cdot \frac{\sigma_{C}}{\bar{C}}+\varepsilon_{1} \quad \text { with } \varepsilon_{1}=\frac{\varepsilon_{1}^{\prime}}{\bar{Q}^{2} \cdot \bar{C}^{2}}
$$

By introducing variation coefficients of $Q, C v_{Q}=\frac{\sigma_{\Delta Q}}{\bar{Q}}$, and C, $C v_{C}=\frac{\sigma_{\Delta C}}{\bar{C}}$, we get:

$$
\frac{\sigma_{\Phi}^{2}}{\bar{Q}^{2} \cdot \bar{C}^{2}}=C v_{C}^{2}+C v_{Q}^{2}+2 \rho_{Q, C} \cdot C v_{C} \cdot C v_{Q}+\varepsilon_{1}
$$

Now considering mean mass discharge:

$$
\bar{\Phi}=\bar{Q} \cdot \bar{C}+\sigma_{Q, C}=\bar{Q} \cdot \bar{C} \cdot\left(1+\rho_{Q, C} \cdot C v_{Q} \cdot C v_{C}\right)
$$

By stating $\varepsilon_{2}=\rho_{Q, C} \cdot C v_{Q} \cdot C v_{C}$ we get:

$$
\bar{Q} \cdot \bar{C}=\frac{\bar{\Phi}}{\left(1+\varepsilon_{2}\right)}
$$

and

$$
\frac{\sigma_{\Phi}^{2}}{\bar{Q}^{2} \cdot \bar{C}^{2}}=C v_{\Phi}^{2} \cdot\left(1+\varepsilon_{2}\right)^{2}
$$

Finally

$$
C v_{\Phi}^{2}=\frac{C v_{C}^{2}+C v_{Q}^{2}+2 \rho_{Q, C} \cdot C v_{C} \cdot C v_{Q}+\varepsilon_{1}}{\left(1+\varepsilon_{2}\right)^{2}}
$$

